\title{
Vietnamese Women's Responses to Domestic Violence in South Korea
}

\author{
Suyeon Park ${ }^{1}$ \\ ${ }^{1}$ Department of Criminal Justice, State University of New York at Plattsburgh, Plattsburgh, USA. \\ Correspondence: Suyeon Park, Department of Criminal Justice, State University of New York at Plattsburgh, \\ Plattsburgh, NY 12901, USA.
}

Received: August 8, 2018

Accepted: August 20, 2018

Online Published: August 27, 2018

doi:10.20849/ajsss.v3i3.439

URL: https://doi.org/10.20849/ajsss.v3i3.439

\begin{abstract}
The purpose of this study is to explore Vietnamese women's responses to domestic violence in South Korea. Based on in-depth interviews with 22 Vietnamese women who marry Korean men, six strategies to cope with domestic violence are identified: enduring, escaping, confronting, negotiating, getting help from informal networks, and seeking assistance from formal sources. This study presents that informal social networks are critical in the process of help seeking for abused Vietnamese women.
\end{abstract}

Keywords: domestic violence, response to abuse, Vietnamese women, Korea

\section{Introduction}

South Korea (hereafter, Korea) has experienced a significant increase in the number of international marriages over the past two decades. According to recent statistics, international marriages rose from $1.2 \%$ in 1990 to $10 \%$ of all new marriages in 2014. The majority of international marriages (84\%) are between Korean men and foreign women from China and Southeast Asian Countries such as Vietnam, Cambodia, and the Philippines (Statistics Korea, 2015).

It has been reported that immigrant women who marry Korean men experience high levels of domestic violence (Byun et al., 2008; Choi \& Byoun, 2014; Seol et al., 2005; Seol, Lee, \& Cho, 2006). The nationwide survey of 948 immigrant women indicated that $31 \%$ of the women reported verbal abuse, $26.5 \%$ reported physical abuse, and $23.1 \%$ reported sexual abuse by their Korean husbands during the past 12 -month period. The survey also noted a much higher prevalence rate of domestic violence among separated or divorced immigrant women groups. During the last 12-month period before separation or divorce, separated or divorced immigrant women reported experiencing verbal abuse (70 to $80 \%$ ), physical abuse (more than 50\%), and sexual abuse (more than $40 \%$ ). However, only $10 \%$ of immigrant wives reported domestic violence to the police and 13 to $14 \%$ used a shelter or hotline for immigrant women (Seol et al., 2005).

Although there have been several studies on domestic violence among immigrant women in Korea (Byun et al., 2008; Choi \& Byoun, 2014; J. Lee, Lee, \& Park, 2016; Park \& Morash, 2017), little is known about how immigrant women act to deal with domestic violence. To address this gap, this study explores Vietnamese women's responses to domestic violence, focusing on how they try to gain safety and maximize their life options.

Vietnamese women are the second largest group of foreign wives in Korea, accounting for $29.4 \%$ of all foreign wives in 2014 (Statistics Korea, 2015). The largest group of foreign wives comes from China and most of those are of Korean heritage. They are bilingual in Chinese and Korean and are familiar with the Korean culture (S. Kim, 2003). In contrast, most Vietnamese women experience difficulties in adjusting to Korean culture and have little or no Korean language proficiency (Chae, Park, \& Kang, 2014; Thao, 2016). Thus, understanding how battered Vietnamese wives cope with abuse would help to improve knowledge on their strategies and resources and to develop effective interventions for Vietnamese women in abusive relationships.

\section{Literature Review}

Contrary to the common perception that abused women are passive and helpless, recent studies have documented that they actively seek help from formal or informal sources and employ a wide variety of strategies to deal with domestic violence and establish their safety (Brabeck \& Guzman, 2008; Gondolf \& Fisher, 1988; Hutchison \& Hirschel, 1998; Kaukinen, 2004; Merritt-Gray \& Wuest, 1995; Meyer, 2011). Battered women are more likely to 
seek help as violence becomes more frequent and severe (Gondolf \& Fisher, 1988) and utilize the different methods to address abuse, including formal and informal help seeking, using faith/religion, placating the abuser, accepting fate/karma, resistance, and fleeing (Bhuyan, Mell, Senturia, Sullivan, \& Shui-Thornton, 2005; Brabeck \& Guzman, 2008; Goodman, Dutton, Weinfurt, \& Cook, 2003; Yingling, Morash, \& Song, 2015).

Women's response to abuse is often affected by their social conditions and available personal resources (Dutton, Orloff, \& Hass, 2000; Ellsberg, Winkvist, Pena, \& Stenlund, 2001; West, Kantor, \& Jasinski, 1998). Immigrant women often face diverse challenges, including social isolation, language barriers, and lack of the social support system (Abraham, 2000; Y. Lee \& Bell-Scott, 2009). These conditions affect their choice in responding to abuse.

Very few studies have explored Vietnamese women's coping styles for life stress in Korea (C. Kim \& Lee, 2016; Thao, 2016). Based on a survey of 301 Vietnamese women, Thao (2016) found that family life stress is positively associated with depression, and the effect of family life stress on depression is mediated by avoidance coping style. In another study of 182 Vietnamese women on life stress and coping styles, C. Kim and Lee (2016) found that women mainly used assistance seeking and problem avoidance to cope with life stress. However, neither study directly focused on women's coping strategies to domestic violence.

The present study, therefore, explores the different strategies developed by Vietnamese women as a response to domestic violence. Specifically, abused Vietnamese women's efforts to seek help from formal and informal sources and their utilization of personal strategies are documented.

\section{Methods}

\subsection{Sample}

Participants in this study were Vietnamese women over age 18 who married Korean men and had a history of domestic violence by their Korean husbands or in-laws. Participants were purposively recruited from women referred from shelters, social service agencies, and other study participants to ensure sample diversity, which resulted in a total of 22 participants.

Among the 22 Vietnamese women, 20 (91\%) migrated to Korea in order to marry. Two women (9\%) entered Korea as unskilled foreign workers, met, and married Korean men. The women's age ranged from 20 to 38 years, with an average of 26.9 ( $\mathrm{SD}=4.6)$. Their Korean husbands were substantially older than they were. The average age of their husbands was 45 years, ranging from 35 to 53 years $(\mathrm{SD}=4.9)$. More than half of the women $(15$ or $68 \%$ ) did not complete high school, although there were 5 women $(23 \%)$ who graduated high school and 2 women $(9 \%)$ who reached college level. While over half of the women (12 or 54.5\%) lacked information about the household income of their families, women with this information reported that the average monthly household income ranged from $\$ 125$ to $\$ 4,500$, with an average of $\$ 1,695$.

All but one woman (21 or 95.5\%) reported physical abuse by their Korean husbands. 4 women (18.2\%) experienced physical abuse by both their husbands and in-laws and 1 woman $(4.5 \%)$ reported physical abuse from just her in-laws. All women experienced verbal abuse by their husbands or in-laws. More than one third of the women ( 9 or $40.9 \%$ ) experienced sexual abuse by their husbands.

At the time of the interview, 9 women (40.9\%) were living with their husbands, $12(54.5 \%)$ were separated, and $1(4.5 \%)$ was divorced. Women had been with their husbands for 1 month up to 9 years, with an average union of 2.5 years. Nine women (40.9\%) had no children, whereas the rest had 1 (9 or $40.9 \%)$ or $2(4$ or $18.2 \%)$ children with their husbands. Nine women (40.9\%) were employed at the time of the interview, but 6 of them had started working after leaving their spouses. Six women (27.3\%) resided in rural areas during their marriages.

\subsection{Data Collection \& Analysis}

The study focuses on a sensitive topic with a vulnerable group of women. After the research protocol was approved by the IRB, data were collected through in-depth interviews with 22 Vietnamese women between June and August 2008. All interviews were conducted at private places chosen by the participants and informed consent forms in both Korean and Vietnamese were given to the participants before the interview. Each interview took one to two hours. All interviews were conducted in either Korean or Vietnamese. Bilingual interpreters assisted in the interviews with participants who preferred to use Vietnamese. In the interview, women explained the types of abuse perpetrated by their husbands or in-laws, strategies to cope with abuse, sources of help used by them, and the process of help seeking.

Individual interviews were audio taped with the women's consent, transcribed verbatim, and then translated into English. Interviews were entered into NVIVO to facilitate the coding and analysis. Interview transcripts were analyzed using line-by-line coding and constant comparison method to discover emergent themes and patterns 
(Charmaz, 2006). To ensure confidentiality pseudonyms were used.

\section{Findings}

From the women's descriptions six strategies to cope with domestic violence were identified: enduring, escaping, confronting, negotiating, getting help from informal networks, and seeking assistance from formal sources.

\subsection{Enduring}

Enduring abuse was the most common strategy employed by women. Nearly all women reported that at one point they had used this strategy regardless of whether they still lived with their violent husbands or left abusive relationships. While enduring abuse, women remained silent, observed the abusers' mood, and avoided any behavior or attitude what would result in the potential violence. Women reported fear of further abuse, isolation, and lack of social support as reasons for remaining quiet. For example, Cúc noted that "I really wanted to run away but I had to endure and stay at home as I had no acquaintance or anyone to help me. I just thought that enduring and waiting would make things better."

As a result of violence, women lived with constant fear and anxiety. They described this experience as walking on eggshells around their husbands and in-laws. Mai commented that she was continually watchful for early warning signs of abuse: "My heart throbbed wildly and I felt so insecure whenever he was drunk because of his repeated violence. Also I was so worried that he might beat, shout or swear at me."

Under these circumstances, women sought to avoid getting into situations that might trigger abuse by being submissive or acting in ways their husbands and in-laws preferred. For example, Huyền stopped seeing Vietnamese friends in the neighborhood because her husband did not want to her to get along with them. Quỳnh never touched any of her mother-in-law's food or belongings because it might set a pretext to her mother-in-law.

\subsection{Escaping}

Leaving the scene to escape abuse was another common strategy used by women. When physical abuse was severe, about three quarters of women (16 or $72.7 \%$ ) left the scene or their home for at least one night to get protection. About a quarter of the women (5 or $22.7 \%$ ) reported leaving their home several times. They sought refuge by fleeing to a friend's or neighbor's home, hiding themselves in another room, or staying in another place away from their abusers during abusive incidents or in anticipation of abuse escalation. For example, Lý explained,

Once my father-in-law scolded me severely as I came home late with my baby after a visit to my friend's house. I cried a lot as I was afraid. Then, my mother-in-law accused me extensively and my husband beat me saying that it was too noisy. I ran away to my friend's that night as I was too scared. I meant to go back home when his anger had subsided.

Women disclosed that temporarily leaving home would often bring more violence or more control over women's movements and association. Abusive husbands followed women to the places of refuge and threatened to harm them. Thúy who stayed in her Vietnamese friend's house overnight recalled that her husband who was drunk came to her friend's place with a hammer and tried to force his way to her house. Lý described how her husband and in-laws exerted more control over her movements after her return: "My parents-in-law would not let me go anywhere after I came back home. Going out became even more difficult." As Langford (1996) suggested, this strategy was usually "a temporary response" (p.379) to avoid abuse, but led to leaving abusive relationships in some cases of obtaining help from formal or informal sources.

\subsection{Confronting}

About a third of the abused women ( 7 or $31.8 \%$ ) challenged their husbands or in-laws either verbally or physically. They resisted the abuse perpetrated by their husbands or in-laws by mainly arguing or talking back to them. It often escalated the situation and resulted in abuse. For example, Thanh commented that "sometimes I talked back and fought if his verbal abuse went too far. But on such occasions, his violence occurred."

While fighting back verbally was more common among women, only one woman (4.5\%) protested against the abuse physically. Anh reported threatening to use a weapon against her husband:

Once my mother-in-law scolded me too much when he was away and I talked back to her. Then my husband came and seeing this, beat me wildly. I resented and got angry so I went to the kitchen to bring a knife and I told him that I would kill him.

She said that "He had me kneel down to ask for forgiveness" after beating her nearly to death.

\subsection{Negotiating}


About a fifth of the women (4 or 18.2\%) attempted to negotiate with their abusive husbands or in-laws. As described above, while the women's leaving home resulted in more violence or control, in a few cases, it provided them opportunities to negotiate things their husbands or in-laws had restricted.

Four women who had stayed at the shelter returned home when their husbands promised to stop the abuse. One of them, Thúy described that "my husband persuaded me to drop a lawsuit for divorce and live with him again. He promised that he would never hit me and would treat me with respect." Some women asked for allowance to have more living expenses or their husbands to seek marriage counseling. Giang who experienced abuse from her mother-in-law asked for moving out of her mother-in-law's house to establish a separate residence, but her in-laws refused her request.

\subsection{Getting Help from Informal Networks}

More than three quarters of the abused women (17 or $77.3 \%)$ reported engaging in informal help seeking. They disclosed their abuse experiences to friends (12 or $54.5 \%$ ), relatives (4 or $18.2 \%)$, or neighbors ( 3 or $13.65 \%$ ) and asked for emotional support, advice, resources, and assistance. In a few cases, women sought assistance from marriage brokers ( 2 or $9.1 \%$ ), a Korean language teacher ( 1 or $4.5 \%$ ), or a pastor ( 1 or $4.5 \%)$.

Women revealed that they turned to informal sources when they realized that they might face a life-threatening situation. They also thought that just tolerating the situation and complying with their abuser's wishes could not stop abuse. In this situation, the most commonly used informal sources of help were friends and relatives. Huyền described how she obtained assistance from her friend:

I didn't dare to think that I could leave the house. But his violence went more and more serious and later it became more horrible than earlier and I thought that this would kill me at any time. I felt so insecure everyday. When my Vietnamese friend in the neighborhood asked what was happening, I told her about my husband's abuse. She was also married to a Korean man and their marriage was a happy one. She gave me information and the telephone number to the Migrant Workers Center. She accompanied me to the Center by bus and later the Center introduced me to the Shelter.

Other women similarly recalled friends or relatives who listened, offered places for them to stay, gave them information about where they could get help, and accompanied them to obtain social services. While they turned to friends or relatives in Korea, most of them kept their abuse hidden from their parents in Vietnam because they did not want to cause their parents distress.

Of the 3 women who turned to their neighbors, 2 of them called their neighbors to ask to take them the emergency room for stitches because they had injuries caused by physical abuse from their husbands. The other woman sought help from the neighbor who had known her husband for a long time to tell him not to abuse her. Two women who sought help from a pastor and a Korean language teacher respectively deemed them to be very helpful in connecting abused women to social services.

Although the majority of the women found informal help seeking to be helpful, two women who sought help from their marriage brokers reported that they failed to get help from them. They had no immediate personal network of friends or relatives except for marriage brokers in Korea. Brokers advised them to just tolerate the situation and stay in abusive relationships when they disclosed their problems and asked for help. A broker told one woman who had a child that "you might not be able to see or raise your child if you divorced." These women were not able to get information about or access social services.

\subsection{Seeking Assistance from Formal Sources}

Most of the women (18 or $81.8 \%$ ) reported accessing formal sources of help. Specifically, more than three quarters of the abused women (17 or $77.3 \%$ ) used advocacy services including shelters (16 or $72.7 \%$ ), hotlines (5 or $22.7 \%$ ), and other social service agencies ( 5 or $22.7 \%$ ). The high proportion in obtaining advocacy services might be a result of the reliance on social service agencies in recruiting study participants. More than a third of the women ( 8 or $36.3 \%$ ) called the police for help though two more women had contacts with police due to other persons' calling.

As Huyền described above, seeking help from informal sources often provided links to social service agencies. Of the 17 women who received advocacy services, 14 women $(82.3 \%)$ were referred to social service agencies or contacted them on their own after receiving information on formal sources of assistance from their social networks.

Most women who utilized advocacy services felt it was helpful to contact shelters or other social service agencies. Shelters provided them with safe housing, counseling, legal support, and Korean language education. 
Oanh said, "The shelter provided me accommodation and meals and taught me Korean. When staying at the shelter, my mind was much more at ease than when I was staying at my husband's." Anh stated that she was informed of her legal right as a victim of domestic violence after she contacted social services:

I talked to a staff from the Korea Women's Hot Line about my abuse. It was only then that I found that I could get help as a victim of domestic violence... I talked about discrimination and suffering experienced by victims of domestic violence and migrant females and acquired information... During my divorce and stay at the shelter, I learned that there were so many things that I could not handle on my own such as citizenship, remaining in the country, and parental rights related to divorce.

Women described the reasons for calling the police. Seven women (87.5\% of the 8) reported that they contacted the police to stop the incident and four of them called the police repeatedly. Thúy explained,

I called the police three or four times. I did so not because I wanted the police to send him to jail, but because I wanted the police to stop him from hitting me. For myself, it was hard to endure his violence. I was afraid of him. I didn't know how to call the police for my first two years in Korea. My close friend who was my neighbor gave me information on how to call the police (call 112).

Two women (25\% of the 8 ) had contacts with the police due to concern for their children's safety and wellbeing. Thảo called the police when her mother-in-law prevented her from taking her sick child to the doctor. However, she never called the police when she experienced physical abuse by her husband or mother-in-law. Hạnh contacted the police to look for her son after her husband left home with him while she was away at work. She didn't know where her child was.

With regards to the effect of calling the police, four women $(50 \%$ of the 8$)$ felt that the police visits had a calming effect on their husbands though their behaviors and attitudes did not change. In some cases, calling the police resulted in the opposite of calming their abusers down. For example, Hạnh who previously reported abuse to the police noted that her husband used even more violence than before to prevent her from calling the police when he beat her again.

\section{Discussion}

This study explored Vietnamese women's responses to domestic violence. Consistent with the findings from earlier research (Bhuyan, Mell, Senturia, Sullivan, \& Shui-Thornton, 2005; Brabeck \& Guzman, 2008; Goodman, Dutton, Weinfurt, \& Cook, 2003; Yingling, Morash, \& Song, 2015), Vietnamese women in this study utilized various strategies to address domestic violence, from private strategies to help seeking from formal and informal sources.

All Vietnamese women initially relied on private strategies rather than seeking outside help. Enduring abuse was the most common method used by women. Women tried to remain quiet, monitor their abusers' mode, and avoided all kinds of potential triggers for the prevention of abuse. Escaping was also a common strategy used by women. Although this strategy was a temporary solution to leave the scene for safety, it provided an opportunity for some women to end abusive relationships or negotiate with their abusive husbands. In such cases, the women obtained outside assistance such as shelters and social support before leaving abusive relationships or negotiating with their abusers. Abused women, in some cases, confronted their abusers either verbally or physically, but this strategy often led to an escalation of violence.

Most Vietnamese women in this study began seeking help from their immediate personal networks when they realized that their personal strategies such as enduring or confronting could not stop the violence. The behaviors of their abusers were unpredictable and became more severe; as a result, women felt that they faced life-threatening situations. These finding are similar to what Huisman (1996) found from a study on Asian American women who sought help only when the violence was severe.

Consistent with previous studies (Kyriakaris, 2014; Sullivan \& Bybee, 1999), this study suggested that informal social networks were critical in the process of help seeking for abused Vietnamese women. Supportive social networks helped battered women to be safe from violence and make connections with other formal sources. The examples of women who did not obtain the needed help from their marriage brokers showed that women's experiences with their social networks influenced their subsequent help seeking behaviors.

The findings from this study should be considered in light of several limitations. First, the sample of participants was not randomly chosen. Therefore, the findings cannot be generalized to all Vietnamese women who marry Korean men. Another limitation was related to difficulties in recruiting participants who did not use advocacy services. Most participants were recruited through referral by shelters, social service agencies, and other study participants and thus the majority of them obtained advocacy services. To develop a more comprehensive 
understanding of women's responses to abuse, it would be recommended to replicate this study by increasing the sample size of participants who did not seek formal help. Further research is also needed on various barriers for seeking help among abused immigrant women to develop effective interventions for immigrant women in abusive relationships.

\section{References}

Abraham, M. (2000). Isolation as a form of marital violence: The South Asian immigrant experience. Journal of Social Distress and the Homeless, 9(3), 221-236.

Bhuyan, R., Mell, M., Senturia, K., Sullivan, M., \& Shiu-Thornton, S. (2005). "Women must endure according to their karma" Cambodian immigrant women talk about domestic violence. Journal of Interpersonal Violence, 20(8), 902-921.

Brabeck, K. M., \& Guzmán, M. R. (2008). Frequency and perceived effectiveness of strategies to survive abuse employed by battered Mexican-origin women. Violence Against Women, 14(11), 1274-1294.

Byun, W., Lee, M., Kim, H., Hwang, J., \& Lee, S. (2008). Domestic violence against marriage immigrants and support enhancements. Seoul: Korean Women's Development Institute.

Chae, S. M., Park, J. W., \& Kang, H. S. (2014). Relationships of acculturative stress, depression, and social support to health-related quality of life in Vietnamese immigrant women in South Korea. Journal of Transcultural Nursing, 25(2), 137-144.

Charmaz, K. (2006). Constructing grounded theory: A practical guide through qualitative analysis. London: Sage Publications.

Choi, G., \& Byoun, S. (2014). Domestic violence against migrant women in South Korea: Addressing the needs of a uniquely situated victim population in domestic violence policy. International Social Work, 57(6), 645-660.

Dutton, M. A., Orloff, L. E., \& Hass, G. A. (2000). Characteristics of help-seeking behaviors, resources and service needs of battered immigrant Latinas: legal and policy implications. Georgetown Journal on Poverty Law \& Policy, 7, 245-305.

Ellsberg, M. C., Winkvist, A., Peña, R., \& Stenlund, H. (2001). Women's strategic responses to violence in Nicaragua. Journal of Epidemiology \& Community Health, 55(8), 547-555.

Gondolf, E. W., \& Fisher, E. R. (1988). Battered women as survivors: An alternative to treating learned helplessness. Lexington, MA: Lexington Books.

Goodman, L., Dutton, M. A., Weinfurt, K., \& Cook, S. (2003). The intimate partner violence strategies index: Development and application. Violence Against Women, 9(2), 163-186.

Huisman, K. A. (1996). Wife battering in Asian American communities: Identifying the service needs of an overlooked segment of the US population. Violence Against Women, 2(3), 260-283.

Hutchison, I. W., \& Hirschel, J. D. (1998). Abused women: Help-seeking strategies and police utilization. Violence Against Women, 4(4), 436-456.

Kaukinen, C. (2004). The help-seeking strategies of female violent-crime victims: The direct and conditional effects of race and the victim-offender relationship. Journal of Interpersonal Violence, 19(9), 967-990.

Kim, C., \& Lee, H. S. (2016). Life stress and coping style for ctress of Vietnamese married immigrant women. Journal of Korean Academy of Community Health Nursing, 27(2), 173-182.

Kim, S. J. (2003). The economic status and role of ethnic Koreans in China. In Borgatta, C. F., \& Choi, I. (Eds.), The Korean Diaspora in the World Economy (pp. 101-127). Peterson Institute for International Economics.

Kyriakakis, S. (2014). Mexican immigrant women reaching out: The role of informal networks in the process of seeking help for intimate partner violence. Violence Against Women, 20(9), 1097-1116.

Langford, D. R. (1996). Predicting unpredictability: A model of women's processes of predicting battering men's violence. Research and Theory for Nursing Practice, 10(4), 371.

Lee, J., Lee, R., \& Park, M. (2016). Fathers' alcohol use and spousal abuse and mothers' child abuse in multicultural families in South Korea: The mediating role of acculturation and parenting stress. Children and Youth Services Review, 63, 28-35.

Lee, Y. M., \& Bell-Scott, P. (2009). Korean immigrant women's journey from abused wives to self-reliant women. 
Women \& Therapy, 32(4), 377-392.

Merritt-Gray, M., \& Wuest, J. (1995). Counteracting abuse and breaking free: The process of leaving revealed through women's voices. Health Care for Women International, 16(5), 399-412.

Meyer, S. (2011). Seeking help for intimate partner violence: Victims' experiences when approaching the criminal justice system for IPV-related support and protection in an Australian jurisdiction. Feminist Criminology, 6(4), 268-290.

Park, S., \& Morash, M. (2017). An exploratory study of influences on vulnerabilities to family violence among Vietnamese wives who marry South Korean men. Critical Criminology, 25(1), 1-19.

Seol, D., Kim, Y., Kim, H., Yoon, H., Lee, H. K., Yim, K., Jeong, K., Ju, Y., Han, G. (2005). Foreign wives' life in Korea: Focusing on the policy of welfare and health. Kwachon: Ministry of Health and Welfare.

Seol, D., Lee, H. K., \& Cho, S. (2006). Survey on international marriage female migrants and policy measures for health welfare support. Seoul: Ministry of Gender Equity \& Family.

Statistics Korea. (2015). Current status of international marriage. Retrieved from http://www.index.go.kr/potal/main/EachDtlPageDetail.do?idx_cd=2430

Sullivan, C. M., \& Bybee, D. I. (1999). Reducing violence using community-based advocacy for women with abusive partners. Journal of Consulting and Clinical Psychology, 67(1), 43-53.

Thao, N. T. (2016). Family life stress, coping, and mental health among Vietnamese marriage migrant women in South Korea: A Mixed Methods Study. VNU Journal of Social Sciences and Humanities, 2(2), 194-212.

West, C. M., Kantor, G. K., \& Jasinski, J. L. (1998). Sociodemographic predictors and cultural barriers to help-seeking behavior by Latina and Anglo American battered women. Violence and Victims, 13(4), 361.

Yingling, J., Morash, M., \& Song, J. (2015). Outcomes associated with common and immigrant-group-specific responses to intimate terrorism. Violence Against Women, 21(2), 206-228.

\section{Copyrights}

Copyright for this article is retained by the author(s), with first publication rights granted to the journal.

This is an open-access article distributed under the terms and conditions of the Creative Commons Attribution license (http://creativecommons.org/licenses/by/4.0/). 